\title{
PSEUDOMALIGNANT OSSEOUS TUMOUR OF SOFT TISSUE
}

\author{
A Clinical, Radiological and Pathological Study of Five Cases
}

\author{
L. Angervall, B. Stener, I. Stener and C. Åhrén, Göteborg, Sweden
}

From the Departments of Pathology II and Orthopaedic Surgery, and the Roentgendiagnostic Department I, Sahlgrenska Sjukhuset, Göteborg

Fine and Stout (1956) described four cases of a benign soft-tissue tumour exhibiting sarcoma-like features in its central parts, but mature bone in its periphery. They called this lesion pseudomalignant osseous tumour of soft tissue. Ackerman (1958) described five cases

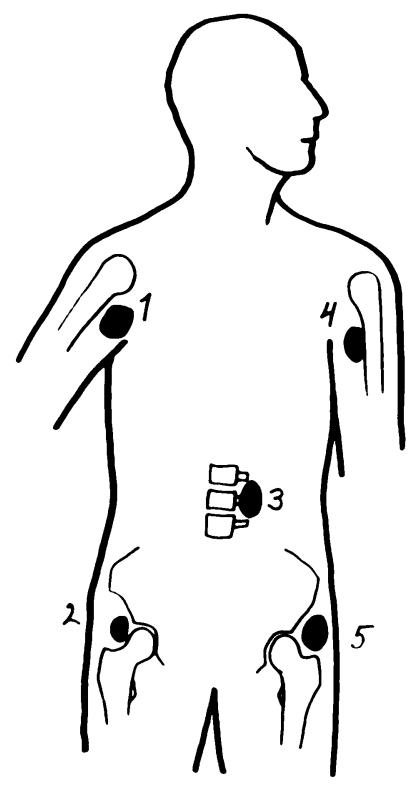

FIG. 1

Localisation of the lesion in the five cases. of apparently the same lesion, but included them in the general category of myositis ossificans. Recently, one case of pseudomalignant osseous tumour of soft tissue has been reported in this Journal (Jeffreys and Stiles 1966).

This paper communicates the results of a clinical, radiological and pathological study of five additional cases (Fig. 1). Several of our observations suggest that this lesion is a reactive condition initiated by an infection.

\section{CLINICAL COURSE AND RADIOGRAPHIC FINDINGS}

Case 1-A girl of nine developed a painful swelling in the right axilla with no history of injury. After three weeks a firm, round, tender mass 5 centimetres in diameter was palpated in the axilla. The mobility of the scapulo-humeral joint was severely impaired. The patient was moderately febrile (about 38 degrees Centigrade) and the erythrocyte sedimentation rate in the first hour was 69 millimetres. Needle biopsy indicated osteoid tissue.

After six weeks, radiography showed a round mass with irregular calcification (Fig. 2). The temperature was still elevated and the sedimentation rate was 91 millimetres. A malignant tumour was suspected. At operation the mass was excised together with adjacent muscle and fat. The greater part of the mass lay in the latissimus dorsi muscle.

The patient's temperature was normal soon after the operation and within two weeks the sedimentation rate had fallen to 22 millimetres. At follow-up a year later she had no discomfort and there was no sign of recurrence.

Case 2-A man of nineteen developed a dull pain in the right hip with no history of injury. Radiography after a few days showed no pathological features. After two weeks a tender lump was palpated under the right tensor fasciae latae muscle. The erythrocyte sedimentation rate was 6 millimetres in the first hour.

After four weeks the patient's clinical state had not changed. The antistreptolysin $\mathrm{O}$ titre was 1,600 units per millilitre. ${ }^{*}$ The antistaphylolysin titre was normal (less than 2 units per

\footnotetext{
* The determination of ASO was performed according to Kalbak (1947) using twofold dilution steps. Titres of 200 units per millilitre or less in single determinations are usually considered as "normal". Non-specific titres were eliminated by selective precipitation of the lipoproteins from the serum with the aid of high molecular weight dextran sulphate in the presence of calcium salts (Burstein and Samaille 1958).
} 
millilitre). The temperature was then observed and proved to be moderately elevated (up to 38 degrees Centigrade).

After six weeks the pain had ceased but the tender lump remained. The sedimentation rate was 8 millimetres. On this occasion radiography showed a round mass, unattached to the skeleton, with irregular calcification (Fig. 3). The mobility of the hip joint was impaired,

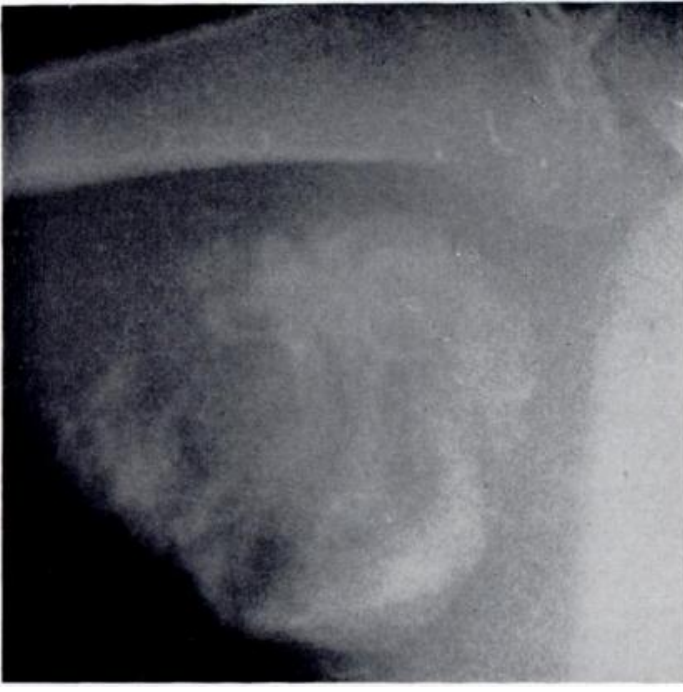

Fig. 2

Case 1-Irregular calcification in right axilla six weeks after onset of symptoms.

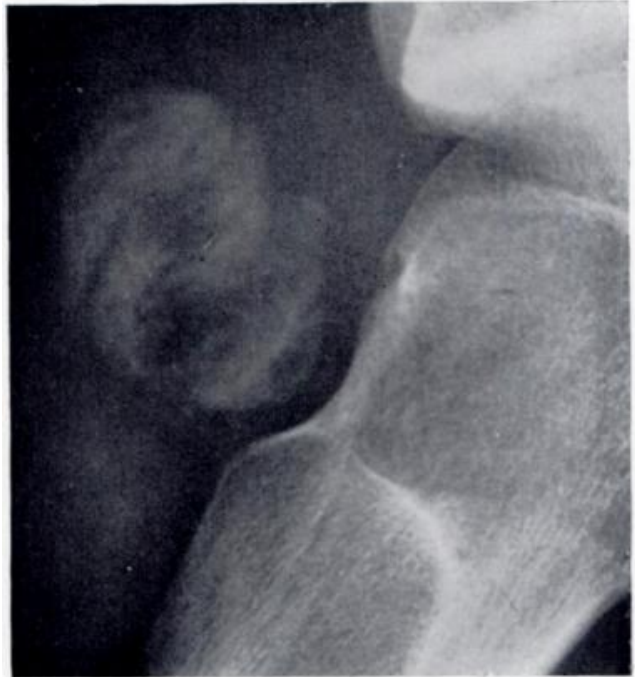

FIG. 3

Case 2-Irregular calcification antero-lateral to right hip joint six weeks after onset of symptoms.

particularly medial rotation. At operation a circumscribed, hard, ovoid mass was found in the periarticular fat under the gluteus medius and minimus muscles. The mass was extirpated together with a layer of surrounding macroscopically healthy tissue. The post-operative course was uneventful.

No sign of recurrence was detected on examination fourteen months after the operation. The patient had no discomfort and the mobility of the hip joint was normal.

Case 3-A man of twenty-one with an infection of the upper respiratory tract developed pain and stiffness of the spine. He gave no history of injury. Two weeks later a tender swelling was found to the left of the lumbar spine. The erythrocyte sedimentation rate was 20 millimetres in the first hour and the white blood count 11,000 per cubic millimetre (normal cell pattern). Radiography showed increased density in an area 2 by 3 centimetres at the level of the transverse process of the third lumbar vertebra. Temperature recordings revealed a slight elevation. During the next few weeks the discomfort diminished, but a tender mass remained.

Eight weeks after onset the antistreptolysin $O$ titre was 400 units per millilitre, the antistaphylolysin titre normal, the sedimentation rate 22 millimetres and the white blood count 7,000 with moderate lymphocytosis ( 40 per cent).

After nine weeks the patient had no fever and mobility was unimpaired. A slightly tender, hard, circumscribed lump about 3 by 5 centimetres was palpated to the left of the lumbar spine. Radiography showed a corresponding area of irregular calcification. At operation the lump was found in the erector spinae muscle; it was excised together with a layer of surrounding muscle. The intact specimen was studied radiographically (Fig. 4), as was a 5 millimetres thick 
slab cut through its centre (Fig. 5). This showed that the peripheral parts consisted of bone tissue with a largely radial arrangement of slender trabeculae. No bone tissue was seen in the central region.

The post-operative course was uneventful. On examination one year later the patient had no discomfort and there was no sign of recurrence.

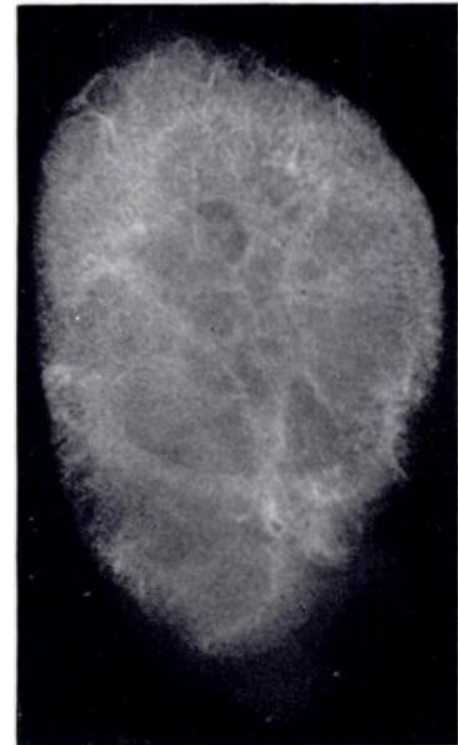

Fig. 4



Fig. 5

Case 3-Radiographs of the intact specimen (Fig. 4), and a 5 millimetre thick slab cut through the centre (Fig. 5). Operation performed nine weeks after onset of symptoms.

Case 4-A boy of eighteen with a cough of several weeks' duration developed pain in the left upper arm; he could not recall any injury. The pain grew more intense and after about a week it was continuous day and night, preventing sleep. By that time an area of the upper arm

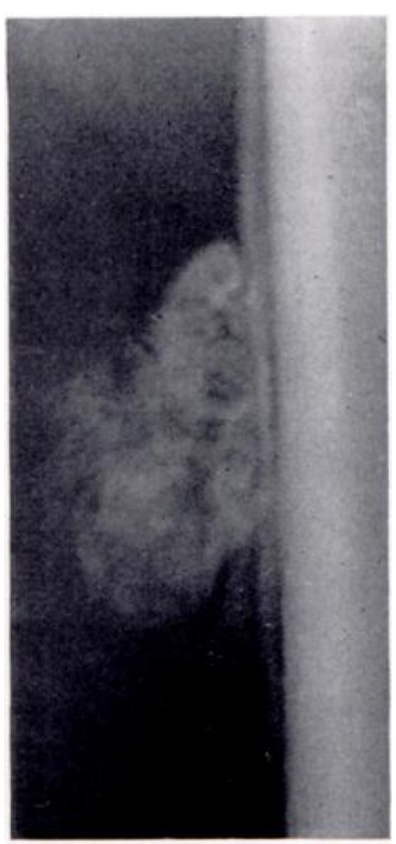

Fig. 6 just below the axilla had become extremely tender. The patient's temperature was not taken.

Four weeks after onset the erythrocyte sedimentation rate was 12 millimetres in the first hour. The pain had diminished, but the affected area was still tender and had become swollen.

After five weeks the pain had ceased, but palpation revealed a tender, round, hard mass apparently attached to the dorsomedial side of the humerus. Radiography showed periosteal ossification and, close to this, irregular calcification in the soft tissue. Osteosarcoma was suspected. The white blood count indicated a slight lymphocytosis (46 per cent).

Six weeks after onset the mass was no longer tender. The antistreptolysin $\mathrm{O}$ titre was $\mathbf{4 0 0}$ units per millilitre. Angiography showed no pathological vessels or increased vascularisation. Plain radiographs taken on this occasion (Fig. 6) revealed that the mass was clearly more calcified than it had been at radiography a week earlier. Tomography showed trabecular formations in

\section{Fig. 6}

Case 4-Periosteal ossification and irregular calcification of soft tissue postero-medial to left humerus six weeks after onset of symptoms. 
the calcified mass indicating ossification. In places the bone was arranged in ring-like formations (Fig. 7). At operation the mass was found beneath the distal part of the coracobrachialis muscle. It was excised together with the adjacent muscle tissue and newly formed periosteal bone. The intact specimen was examined radiographically, as was each of the 3 millimetres thick slabs into which it was then cut. The findings confirmed the tomographic observation of bone spicules in the newly formed mass.

The post-operative course was uneventful. At examination one year later the patient had no discomfort and there was no sign of recurrence.

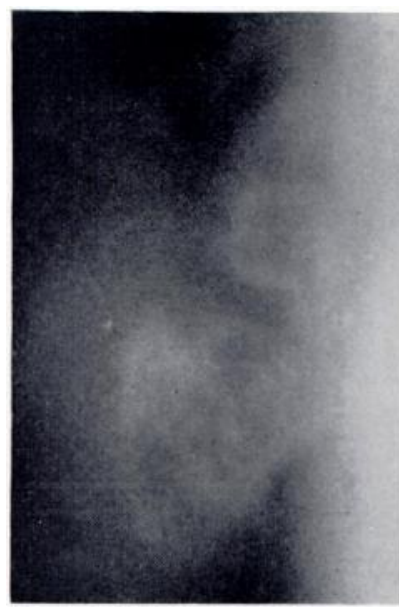

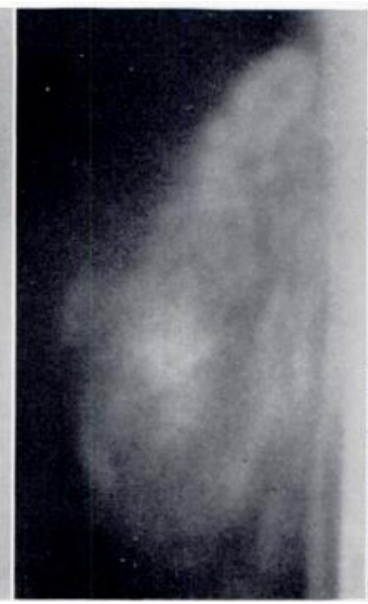

Fig. 7

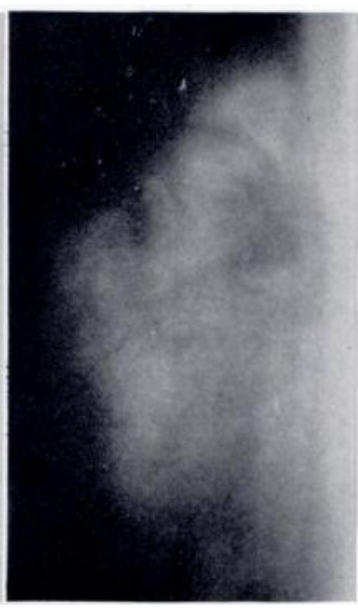

Case 4 - Ring-shaped formations of new bone revealed by tomography.

Case 5-A girl of thirteen developed pain and tenderness in the vicinity of the left hip joint two weeks after a mild cold. These troubles were accompanied by a progressively more pronounced limp. There was no history of injury.

Two weeks after onset she was admitted to hospital. Examination revealed a tender area just above the left greater trochanter, and a fixed abduction deformity at the left hip resulting in functional elongation of the leg by two centimetres. There was also impairment of extension, flexion and rotation. Radiography (Fig. 8) showed an irregularly calcified area above the

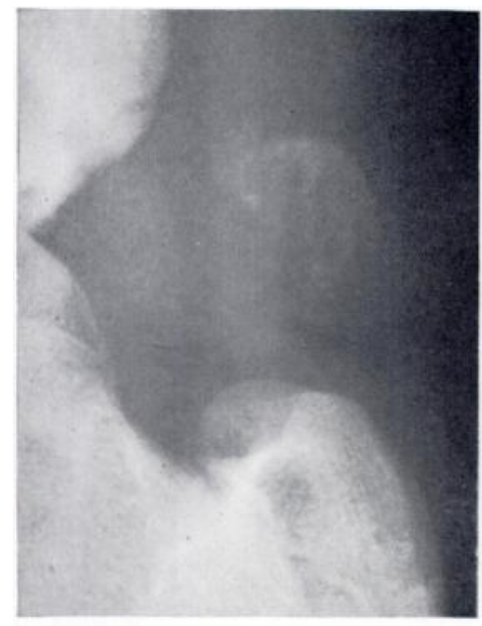

FIG. 8

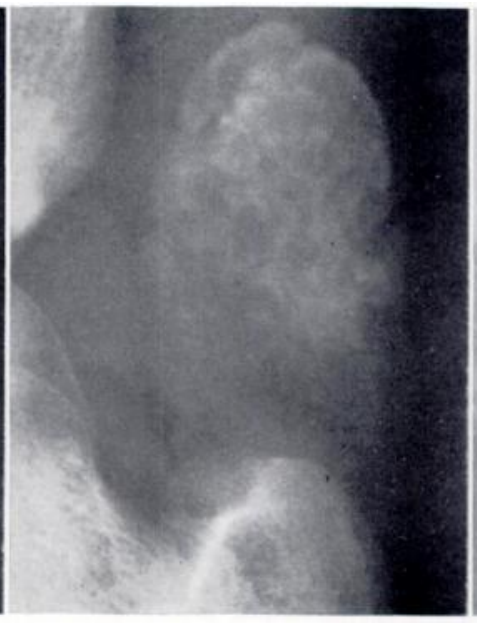

FIG. 9

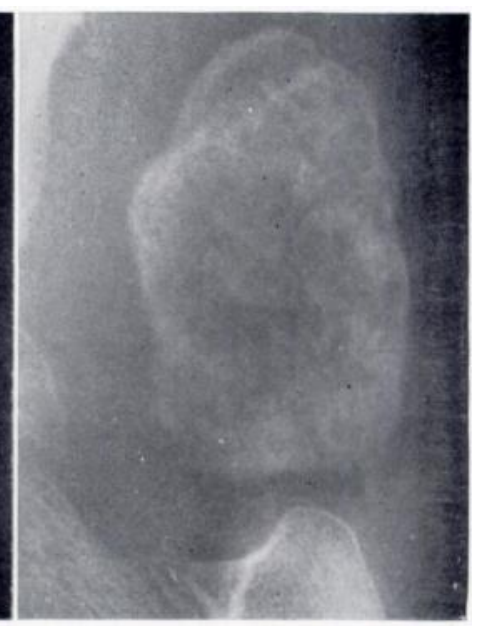

FIG. 10

Case 5-Calcification of mass lateral to left hip joint two weeks (Fig. 8), six weeks (Fig. 9) and cight wceks (Fig. 10) after onset of symptoms.

VOL. 51 B, NO. 4, NOVEMBER 1969 
greater trochanter. The patient was febrile. The antistreptolysin $\mathrm{O}$ titre was 200 units per millilitre.

After five weeks she was still feverish and the affected region was extremely tender. The antistreptolysin $\mathrm{O}$ titre was 400 units per millilitre and the erythrocyte sedimentation rate 45 millimetres in the first hour.



Fig. 11

Case 5-Tomographs of the mass ten weeks after onset of symptoms.

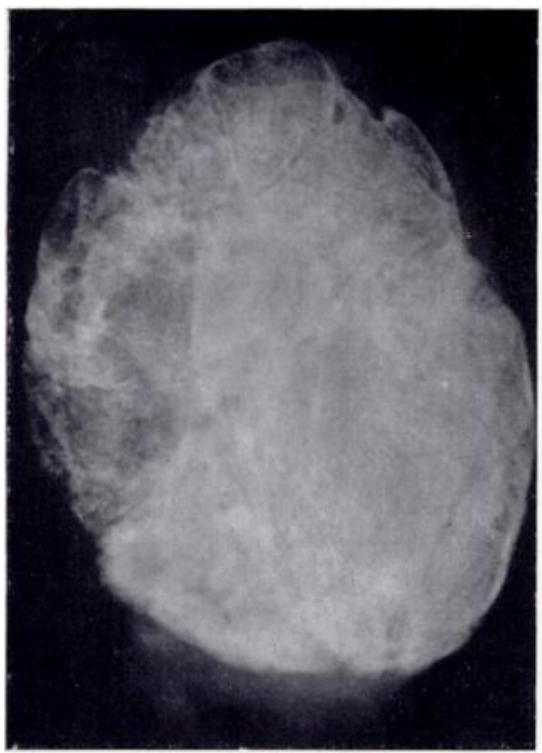

Fig. 12

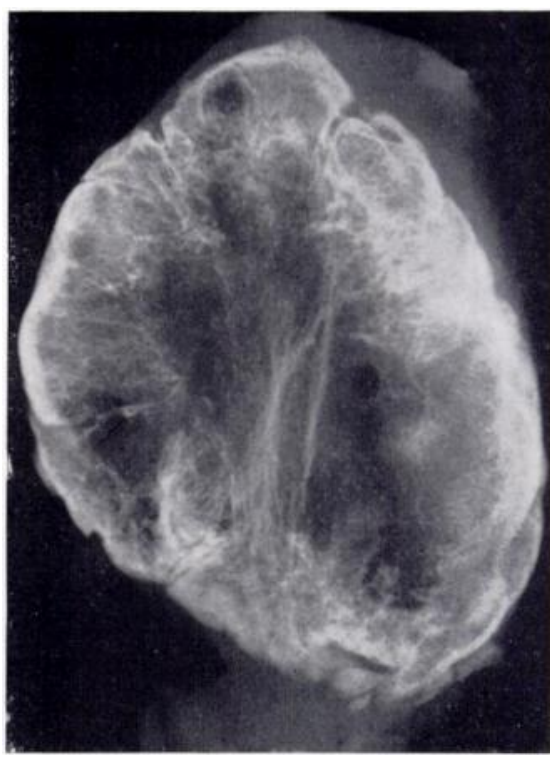

FIG. 13

Case 5-Radiographs of the intact specimen (Fig. 12) and a 5 millimetre thick slab cut through the centre (Fig. 13). Operation performed ten weeks after onset of symptoms.

After six weeks, radiography (Fig. 9) revealed that the area of calcification had grown larger. Its proximal limit was clear-cut, but its distal margin was diffuse.

After eight weeks her temperature was normal and the pain had diminished, but there was still a fixed abduction deformity in the left hip jo:nt and she had a definite limp. The 
antistreptolysin $\mathrm{O}$ titre was 800 units per millilitre, the sedimentation rate 54 millimetres, and the white b ood count 4,800 with a slight lymphocytosis (44 per cent). Radiography (Fig. 10) showed that the area of calcification had grown still larger and was now clearly demarcated distally as well; spicules of bone were visible.

Ten weeks after onset the patient no longer had any pain but limped as before. The antistreptolysin $\mathrm{O}$ titre was 200 units per millilitre, the sedimentation rate 17 millimetres, and the white blood count 5,000 with a somewhat more marked lymphocytosis (50 per cent). Tomography demonstrated that the ossified tissue was chiefly located in the periphery of the mass (Fig. 11).

At operation a hard lump was found in the anterior part of the gluteus minimus muscle. It was excised together with a layer of surrounding muscle. Radiographs were taken of the intact specimen (Fig. 12) as well as of a 5 millimetres thick slab cut through its centre (Fig. 13).

The post-operative course was uneventful. No sign of recurrence was detected at an examination seven months after the operation. The patient had no discomfort and the mobility of the hip was normal.

\section{PATHOLOGICAL EXAMINATION}

The macroscopic appearance was similar in all five cases: a clearly demarcated, ovoid, hard mass with a maximum diameter of 3 to 5 centimetres. The cut surface (Fig. 14) displayed two distinguishable zones, one peripheral and hard, containing cancellous bone, and the other central and soft, with a greyishwhite or yellowish-white appearance, partly solid, partly oedematous and cystic.

The histological picture was also essentially similar in the five cases. The peripheral zone consisted of mature cancellous bone (Fig. 15). The bone spicules, radially arranged in many places, were covered with a single layer of osteoblasts (Fig. 16). The spaces between the spicules contained loose connective tissue. At the junction between the hard peripheral zone and the soft central region, slender spicules of osteoid tissue were arranged irregularly or in a network, with one or several layers of osteoblasts on their surface. Between the osteoid spicules there was connective tissue with abundant fibroblasts and occasional young osteoblasts. The central soft region consisted in essence of connective tissue with varying cell density. In Cases 1, 2 and 4 (patients operated upon six weeks after the symptoms first appeared) the fibroblasts in very cellular tissue were arranged in some places in parallel, forming irregularly interlacing bundles (Fig. 17), while elsewhere

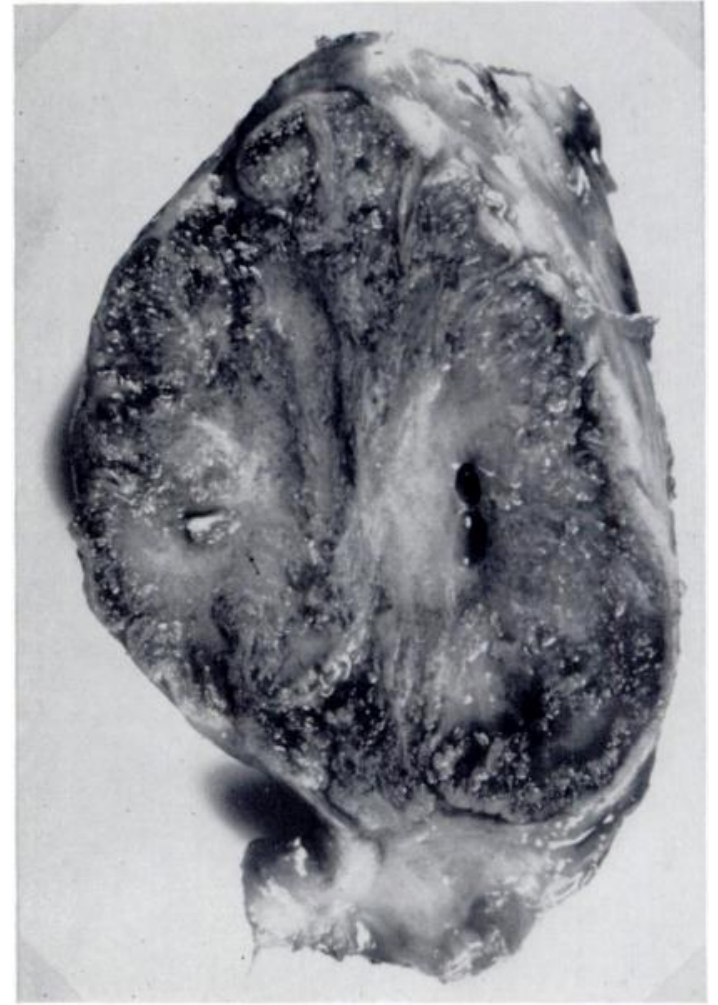

FIG. 14

Case 5-Photograph of the slab used for radiography (compare Figure 13). $(\therefore 1 \cdot 5$. the arrangement was entirely haphazard. The fibroblasts showed some nuclear pleomorphism and occasional mitoses. Clusters of polynuclear giant cells were seen (Fig. 18). The less cellular tissue was partly myxoid with evidence of cystic degeneration, and contained numerous capillary-type vessels of varying calibre. Many of the larger vessels displayed hyalinisation 


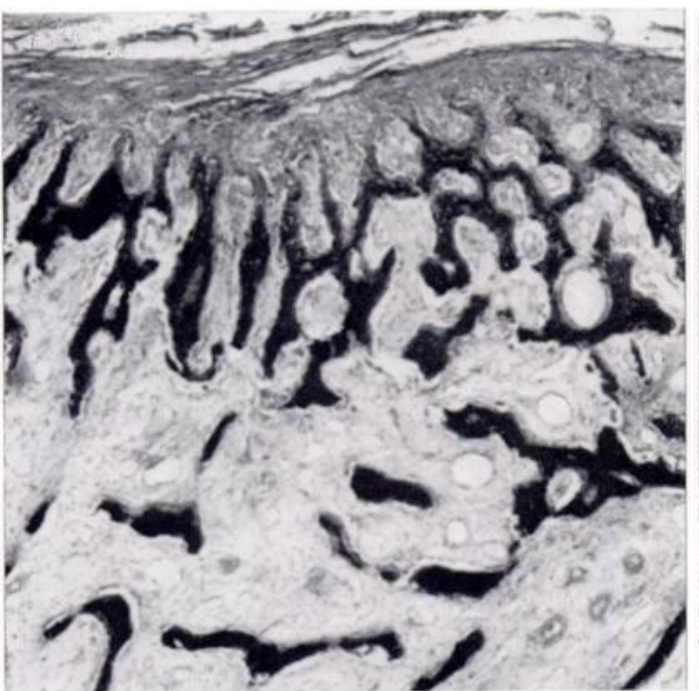

FiG. 15

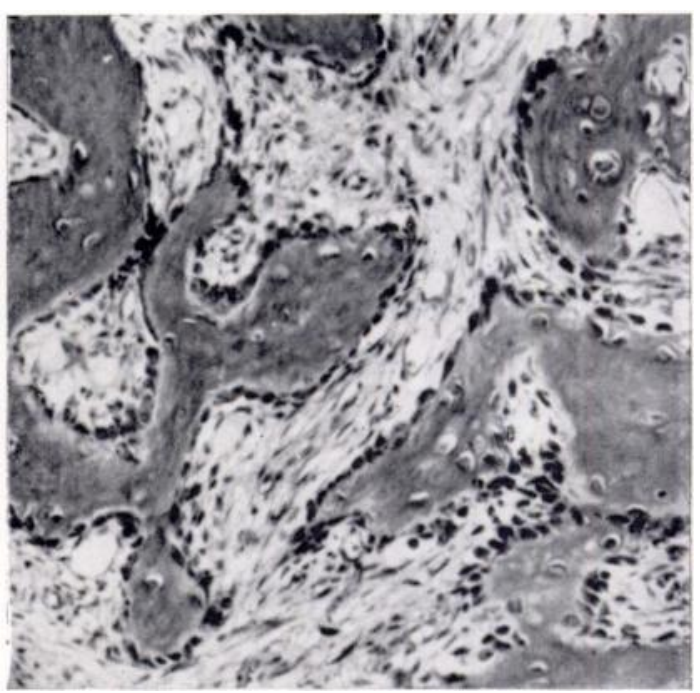

FIG. 16

Case 4. Figure 15-Photomicrograph. Peripheral zone with mature cancellous bone. (Van Gieson, 30.) Figure 16-Photomicrograph. Peripheral zone. Bone spicules covered by single layer of osteoblasts. Loose connective tissue between the spicules. (Van Gieson, $\times 120$.)

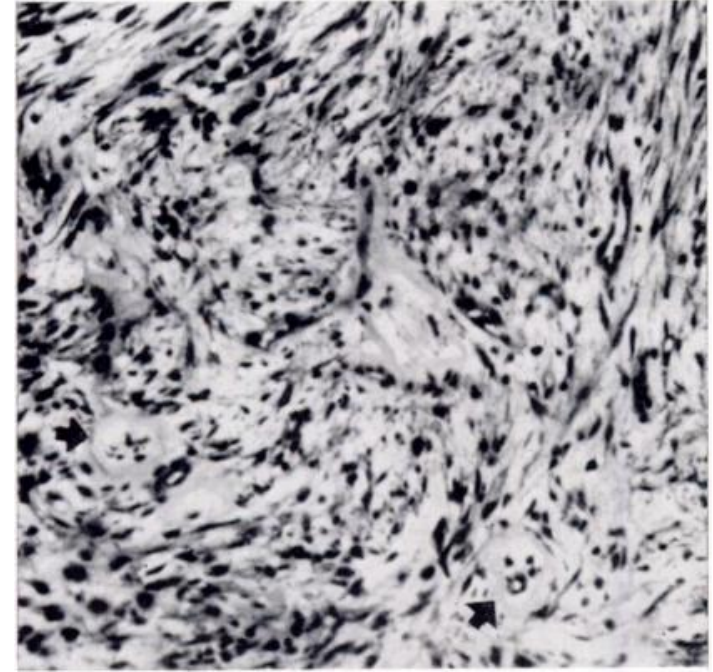

Fig. 17

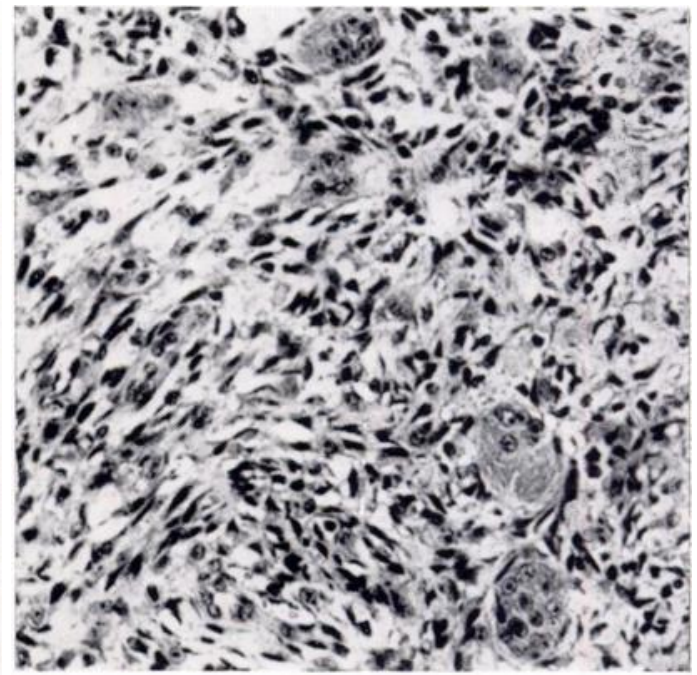

FIG. 18

Case 2. Figure 17-Photomicrograph. Central region with fibroblasts arranged in parallel in irregularly interlacing bundles. Nuclear pleomorphism and occasional mitoses. Vessels with hyaline walls indicated by arrows. (Haematoxylin and eosin, $\times 120$.) Figure $18-$ Photomicrograph. Central region. Irregular arrangement of fibroblasts. Polynuclear giant cells. (Van Gieson, 190.)

(Fig. 17). In Cases 3 and 5 (patients operated upon nine and ten weeks respectively after the symptoms first appeared), the very cellular and less cellular tissues tended to have a regular arrangement, a network of tightly packed fibroblasts being filled with loose connective tissue containing few cells (Fig. 19). Osteoblasts with early osteoid formation were seen here and there in the fibroblast network. A wide capillary-type vessel was often seen in the centre of less cellular tissue (Fig. 20). In some places loose connective tissue merged into denser fibrous tissue with formation of collagen.

No necrosis or signs of early or recent haemorrhage were observed in any of the cases, nor was iron pigment demonstrated (the Prussian blue reaction was negative). 


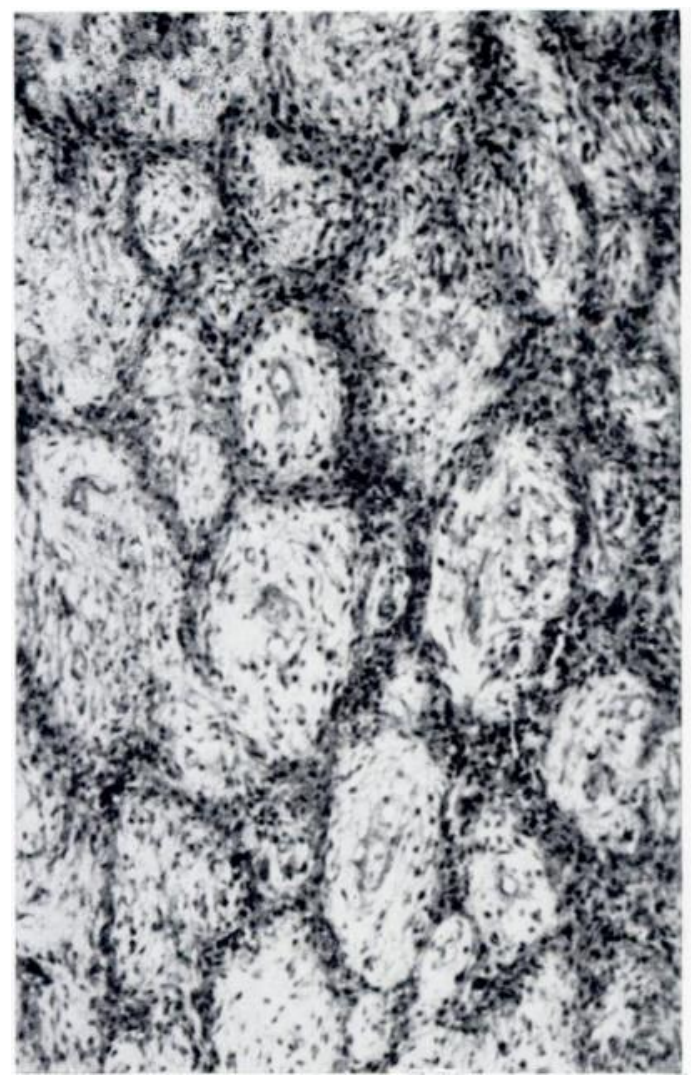

Fig. 19



Fig. 20

Case 5. Figure 19-Photomicrograph. Central region. Network of tightly packed fibroblasts with islands of loose connective tissue containing few cells. Osteoblasts with osteoid formation here and there in the fibroblast network. (Van Gieson, $\times 30$.) Figure 20-Photomicrograph. Central region (compare Figure 19). Wide capillary-type vessels in tissue containing few cells. (Van Gieson, $\times 120$.)

In all five cases the striated muscle and fat tissue surrounding the lesion contained inflammatory cells (lymphocytes and plasma cells), particularly in perivascular location. There was atrophy and fibrosis of the muscle in the vicinity of the lesions. In Cases 3 and 5, islands of inflammatory cells were also found in the central part of the lesion.

\section{DISCUSSION}

In all five cases the morphological appearance of the lesion corresponded to the condition described by Fine and Stout (1956) as pseudomalignant osseous tumour of soft tissue. The term pseudomalignant is justified by the sarcoma-like appearance of the soft central region; the condition has in fact been misinterpreted as an osteosarcoma (Fine and Stout 1956, Jeffreys and Stiles 1966). The overall picture, however, can be readily distinguished from a sarcoma. The characteristic zone phenomenon-with a regular arrangement of mature bone in a peripheral zone and a transitional zone of osteoid tissue next to the central highly cellular region-is quite different from the haphazard arrangement of a malignant tumour (Ackerman 1958).

Ackerman maintained that the genesis is probably traumatic. The present findings suggest another etiology. There was no history of injury in any of the cases and no trace of bleeding was detected on histological examination. The clinical course in these cases rather indicates that the lesion is a reactive condition initiated by an infection. The onset was acute in all the patients, with pain and varying degrees of tenderness at the site of a rapidly occurring 
local swelling. Two of the patients developed these symptoms during respiratory-tract infection, a third two weeks after such an infection. The body temperature was found to be raised in four of the cases (1, 2, 3 and 5); in Case 4 it was not measured during the florid phase. The sedimentation rate was elevated to varying degrees in all five patients. The antistreptolysin O titre was not determined in Case 1, was possibly elevated in Cases 3 and 4 (400) and definitely elevated in Case $2(1,600)$ and Case $5(800)$. The significance of these values is strengthened by the fact that non-specific antistreptolysin $O$ titres had been eliminated by dextran sulphate precipitation of the sera (Burstein and Samaille 1958). Moreover, the good agreement between the antistreptolysin $\mathrm{O}$ titre, the sedimentation rate and the clinical symptoms, especially in Case 5 (Table I), suggests that an infection has played a role in the pathogenesis. The subjective discomfort regressed spontaneously in four cases ( 2 to 5 ). When these patients were operated upon, six to ten weeks after the symptoms first appeared, the pain had ceased and the affected region was only slightly, if at all, tender. The spontaneous course could be followed most closely in Case 5 (Table I).

It is difficult to resolve the relationship between pseudomalignant osseous tumour of soft tissue and myositis ossificans (Jeffreys and Stiles 1966). The genesis of myositis ossificans is usually traumatic, but a non-traumatic form has also been observed. Concerning the latter, Küttner (1910) stated in a fundamental study on myositis ossificans that the few published

TABLE I

Clinical Course in Case 5

\begin{tabular}{|c|cccc|}
\hline $\begin{array}{c}\text { Weeks after } \\
\text { onset of } \\
\text { symptoms }\end{array}$ & $\begin{array}{c}\text { Pain and } \\
\text { tenderness }\end{array}$ & $\begin{array}{c}\text { Raised } \\
\text { body } \\
\text { temperature }\end{array}$ & $\begin{array}{c}\text { Erythrocyte } \\
\text { sedimentation rate } \\
\text { in the first hour } \\
\text { (millimetres) }\end{array}$ & $\begin{array}{c}\text { Antistreptolysin } \\
\text { O titre } \\
\text { in units } \\
\text { per millilitre }\end{array}$ \\
\hline 2 & $\frac{\text { Not determined }}{4}$ & 200 \\
\hline 5 & + & 45 & 400 \\
\hline 8 & - & 54 & 800 \\
\hline 10 & - & 17 & 200 \\
\hline
\end{tabular}

cases were so dissimilar that it was impossible to deduce a relatively uniform clinical picture. Nor had this picture clarified when Küttner's pupil Liebig (1929) published a new review of myositis ossificans. There may indeed be some grounds for including pseudomalignant osseous tumour of soft tissue among the non-traumatic forms of myositis ossificans. The signs of an infectious genesis in the present cases would well justify the term myositis. At the same time, however, the lesion is not invariably found in muscle (Case 2), and it may be advisable to use a term which indicates that the condition differs clinically as well as etiologically from the lesion of traumatic origin that is usually implied by the term myositis ossificans (Gilmer 1963).

The radiographic examination of the surgical specimen in three of the cases (Figs. 4, 5, $12,13)$ clearly illustrates the morbid anatomy with bone formation in a peripheral zone around a central non-ossified region. With the help of tomography the radiologist-bearing in mind that this zone phenomenon is characteristic of pseudomalignant osseous tumour of soft tissue - can make an important contribution to the clinical diagnosis, as in Cases 4 and 5. Osteosarcoma was suspected in Case 4 after the first radiographic examination, but this diagnosis could be eliminated in favour of a pseudomalignant osseous tumour of soft tissue when tomographs demonstrated ring-shaped formations of new bone. The proximity of the lesion to the humeral diaphysis may have elicited the periosteal formation of new bone in this case. In Case 5 the information obtained through repeated radiography (Figs. 8 to 10) suggests 
that the tumour-like mass attained its ultimate size at an early stage-that is, before ossification began. The successive enlargement of the calcified area on the radiographs does not necessarily indicate that the mass itself grew, but simply that the peripheral ossification started in the cranial part and progressed caudally. In this case the mass was excised as much as ten weeks after the onset of symptoms, and it was found that osteoid formation had started even in the central region. The radiographic development of the lesion, taken in conjunction with the appearance of the surgical specimen, suggests that an untreated pseudomalignant osseous tumour of soft tissue ultimately becomes completely ossified (Ackerman 1958).

In Cases 1, 2 and 4, in which the mass was excised six weeks after the onset of symptoms, the central soft region displayed little differentiation and resembled a sarcoma (Fig. 17). Indeed, it brought to mind another pseudosarcomatous lesion, nodular fasciitis. Like pseudomalignant osseous tumour of soft tissue, nodular fasciitis is a tumour-like, fairly circumscribed lesion with rapid growth. It differs, however, with respect to size and location, being smaller as a rule and usually subcutaneous. It should be mentioned, though, that deeper forms involving muscle have also been observed. Nodular fasciitis, too, has often been erroneously diagnosed as a sarcoma (Enzinger 1965). It is not neoplastic, however, but a reactive condition. It seems to us that there are grounds for a similar interpretation of pseudomalignant osseous tumour of soft tissue.

\section{SUMMARY}

1. Five cases of pseudomalignant osseous tumour of soft tissue are reported.

2. Clinical and histological observations suggest that this lesion is a reactive condition initiated by an infection.

3. Tomography is helpful in demonstrating the characteristic peripheral ossification around non-ossified central regions of the lesion.

\section{REFERENCES}

ACkerman, L. V. (1958): Extra-osseous Localized Non-neoplastic Bone and Cartilage Formation (So-called Myositis Ossificans). Journal of Bone and Joint Surgery, 40-A, 279.

Burstein, M., and Samaille, J. (1958): Sur une nouvelle méthode de dosage du cholestérol lié aux $\alpha$ - et $\beta$-lipoprotéines du sérum. Clinica chimica acta, 3, 320.

Enzinger, F. (1965): Recent Trends in Soft Tissue Pathology. In Tumors of Bone and Soft Tissue. p. 315. Chicago: Year Book Medical Publishers Inc.

Fine, G., and Stout, A. P. (1956): Osteogenic Sarcoma of the Extraskeletal Soft Tissues. Cancer, 9, 1027.

Gilmer, W. S., Jun. (1963): Tumors and Tumorlike Lesions of Somatic Tissue. In Campbell's Operative Orthopaedics. Fourth edition, p. 1264. Edited by A. H. Crenshaw. Saint Louis: C. V. Mosby Company.

Jeffreys, T. E., and Stiles, P. J. (1966): Pseudomalignant Osseous Tumour of Soft Tissue. Journal of Bone and Joint Surgery, 48-B, 488.

KalbaK, K. (1947): The Antistreptolysin Reaction. I. Technique. The State Serum Institute, Copenhagen (Denmark).

Kütrner, H. (1910): Die Myositis Ossificans Circumscripta. Ergebnisse der Chirurgie und Orthopädie, 1, 49.

LiebIG, F. (1929): Die Myositis Ossificans Circumscripta. Ergebnisse der Chirurgie und Orthopädie, 22, 501. 